\title{
Academic Detailing for Postpartum Opioid Prescribing
}

Katya Alcaraz Voelker, MD, and Charles Schauberger, MD, MS

Introduction: Overprescribing opioid pain medications has become a major concern in our society due to the increasing rates of substance use disorders and the rate of accidental overdoses. The widespread availability of opioid medications suggests that patients are being prescribed opioids in amounts larger than they require for pain control. Efforts are now being made on a variety of fronts to decrease overprescribing.

Material and Methods: A quality-improvement model was applied to address this concern at one medical center in women being discharged from the hospital following childbirth. The rates and amounts at which opioids were prescribed to this population before and after an academic detailing intervention were compared.

Results: The overall percentage of women who received prescriptions for opioid medications decreased from $100 \%$ to $93 \%$ in cesarean sections $(P=.054)$ and $15 \%$ to $9 \%$ in vaginal deliveries $(P=$ $.03)$. The average prescription size decreased by 5 tablets $(P<.0001)$.

Implications: Simple quality-improvement methods may have a positive impact on opioid prescribing patterns, including decreasing the percentage of opioids postdelivery or the quantity of opioids per prescription. (J Am Board Fam Med 2018;31:944-946.)

Keywords: Childbirth, Drug Overdose, Inappropriate Prescribing, Opioid Analgesics, Pain Management, Quality Improvement

Excessive prescribing of opioid pain medications has been linked to an increased risk of overdose deaths and higher rates of opioid use disorder. Investigators have studied opioid prescription rates and amounts of medications used by patients after various procedures and operations, including childbirth. Jarlenski et $\mathrm{al}^{1}$ found that $12 \%$ of patients filled an opioid prescription after a vaginal delivery. Osmundson and colleagues ${ }^{2}$ reported that $83 \%$ of patients were prescribed opioids after cesarean section and used them for a median of 8 days.

Our review of the literature revealed a paucity of quality-improvement studies that correspond to the

This article was externally peer reviewed.

Submitted 1 March 2018; revised 12 July 2018; accepted 12 July 2018.

From Department of Medical Education (KAV), and Department of Obstetrics and Gynecology (CS), Gundersen Health System, La Crosse, WI.

Funding: none.

Conflict of interest: none declared.

Corresponding author: Katya Alcaraz Voelker, MD, Mail Stop FB2-009, Gundersen Health System, 1900 South Avenue, La Crosse, WI 54601 (E-mail: kalcaraz@gundersenhealth.org). prescribing of opioids and none that related to postpartum prescribing. In 2016, Burton et $\mathrm{al}^{3}$ described a quality-improvement initiative to decrease emergency physician opioid prescribing involving a process of measuring, reporting, and remeasuring that demonstrated significant decreases in the number and size of prescriptions. Our report describes a similar effort to "right-size" prescribing in obstetric patients through a qualityimprovement format of providing baseline data, academic detailing, and remeasurement.

\section{Materials and Methods}

This study was conducted at the Gundersen Medical Center , with a total of 19 delivering providers, including obstetricians, nurse-midwives, and family medicine physicians. Using billing records, we identified all women who delivered from January 1, 2016, through March 31, 2016. Mothers experiencing a stillbirth were excluded. Electronic medical records were used to collect demographic and clinical data, including opioid prescriptions at dis- 
Table 1. Demographic and Clinical Characteristics of Obstetric Patients

\begin{tabular}{lccc}
\hline Characteristic & 2016 & 2017 & $P$ value \\
\hline Total no. patients & 297 & 323 & \\
Age, y, mean (SD) & $29.3(5.0)$ & $29.2(5.0)$ & .90 \\
Parity, median (range) & $2(1$ to 7$)$ & $2(0$ to 10) & .41 \\
$\begin{array}{l}\text { Tobacco use at delivery, } \\
\quad \text { n (\%) }\end{array}$ & $29(9.8)$ & $32(10.1)$ & .90 \\
$\begin{array}{l}\text { Cesarean delivery, n (\%) } \\
\text { Induced labor, n (\%) }\end{array}$ & $53(17.9)$ & $59(18.6)$ & .82 \\
$\begin{array}{l}\text { EPDS score at } \\
\quad \text { discharge, median }\end{array}$ & $1.5(0-17)$ & $2(0-20)$ & .99 \\
$\quad$ (range) & & & \\
\hline
\end{tabular}

SD, standard deviation; EPDS, Edinburgh Postnatal Depression Scale.

*Statistically significant.

charge. Validation was performed in a small number of medical records.

We used a nonpunitive method to send a quality report with pooled baseline data to all delivering providers. Providers could compare themselves with the total group rates individually. "Academic detailing" was performed with providers using a literature review. All questions were answered and the message reinforced. Data collection was repeated for deliveries from January 1, 2017, through March 31, 2017.

\section{Results}

The 2016 baseline group $(\mathrm{n}=297)$ and 2017 remeasurement group $(n=323)$ were similar in age, parity, tobacco use, and Edinburgh Postnatal De- pression Scale scores (see Table 1). The only statistically significant difference noted was a higher rate of induced labor in 2017. However, postpartum opioid prescribing neither increased nor decreased in patients whose labors were induced $(P=$ .67). The number of tablets prescribed per prescription decreased by a median of 5 tablets, and the morphine milligram equivalents prescribed decreased from 171 to $143(P=.001)$.

The preferred postpartum medication was hydrocodone/acetaminophen. Oxycodone-containing prescriptions were provided to 8 patients in 2016 versus 5 patients in the 2017 period; therefore, Figure 1 presents data for hydrocodone prescriptions only.

The percentage of prescriptions for opioids after a cesarean section decreased from $100 \%$ to $93 \%$, a downward trend, but it was not statistically significant $(P=.054)$. However, the number of tablets prescribed decreased significantly $(P=.0002)$. The percentage of prescriptions following vaginal delivery decreased significantly from $15 \%$ to $9 \%(P=$ $.03)$ without a significant change in number of tablets prescribed $(P=.26$; Figure 1$)$.

\section{Conclusion}

Our study showed a decreased number and size of opioid prescriptions following intervention. The improvements noted in our study were probably not entirely secondary to our intervention, given that this time period was associated with a $12 \%$ decrease in prescribing in Wisconsin after initiation of its Prescription Drug Monitoring Program; however, it

Figure 1. Average number of hydrocodone/acetaminophen tablets prescribed before and after academic detailing intervention-cesarean (C/S) and vaginal deliveries.

\section{Lortab Prescriptions}

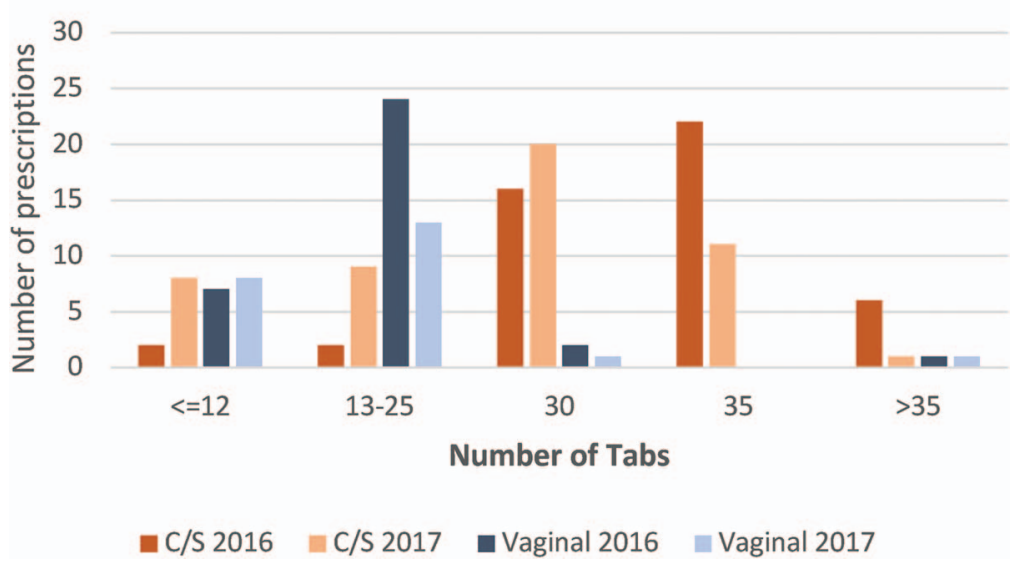


does show a model that is reproducible for prescribing postpartum and for other procedures and patient groups. The availability of opioids in the community must be reduced to combat misuse and its many consequences. The ability to use the electronic medical record for this sort of study has been underused in our opinion and should be explored in much greater depth and breadth.

To see this article online, please go to: http://jabfm.org/content/ 31/6/944.full.

\section{References}

1. Jarlenski M, Bodnar LM, Kim JY, Donohue J, Krans EE, Bogen DL. Filled prescriptions for opi- oids after vaginal delivery. Obstet Gynecol 2017; 129:431-7.

2. Osmundson SS, Schornack LA, Grasch JL, Zuckerwise LC, Young JL, Richardson MG. Postdischarge opioid use after cesarean delivery. Obstet Gynecol 2017;130:36-41.

3. Burton JH, Hoppe JA, Echternach JM, Rodgers JM, Donato M. Quality improvement initiative to decrease variability of emergency physician opioid analgesic prescribing. West J Emerg Med 2016;17: 258-63.

4. Nygren J. Opioid prescriptions fall drastically [news release]. Available from: http://www.thewheelerreport. com/wheeler_docs/files/1106nygrenrev.pdf. Published 2017. Accessed November 28, 2017. 